\title{
NEW TECHNIQUE TO MAKE A PROVISIONAL OF NATURAL TOOTH
}

\begin{tabular}{|l|l|l|l|}
\hline Prosthodontics &
\end{tabular}

Blanca Estela Clinical and Laboratory teacher of the Faculty of Stomatology of the Autonomous Estrada Esquivel University of Puebla Benemérita BUAP(México) \& 10 B Sur\#3720-301 Col Anzures

\begin{tabular}{ll}
\hline Elsa Deni Pérez & $\begin{array}{l}\text { Student of 10th grate Faculty of Stomatology of Autonomous University of Puebla } \\
\text { Hernández* }\end{array}$ \\
Benenemerita BUAP(México) ${ }^{*}$ Corresponding Author
\end{tabular}

\section{ABSTRACT}

Periodontal diseases and dental injuries in most cases cause loss of the alveolar bone that supports the teeth naturally. An alternative proposal when the patient goes to the dental office, especially with a superior incision that has mobility more than grade 3 , caused by some of the two previous reasons, and the dental treatment is already irremediably as the extraction and must be done in the same appointment. One more technique is presented, to elaborate a provisional in a natural way and in the same appointment, so that the patient emotionally sees and feels that he has not lost his tooth drastically or irreparably. It is a natural provisional that must comply with the indications and requirements that the literature marks in a traditional way, only that in this proposal it is a natural tooth.

\section{KEYWORDS}

Natural tooth, dental provisional, interdental felurization.

\section{INTRODUCTION}

Provisional restorations are an integral part of any rehabilitation treatment are used during the preparation of the dental organs and the final restoration. They must fulfill important functions such as; accumulation of dentobacterial plaque, prevents the appearance of gingival hyperplasia, auxiliary to determine the reduction during dental preparation, help occlusal stability, useful as a guide for the shape, contour and color of the final restoration ${ }^{(1)}$ and familiarize the patient with appearance of the restoration, among others; therefore, a properly prepared provisional restoration is important to achieve a successful indirect restoration so, its preparation and adaptation should not be overlooked.

Historically, materials and various techniques for the development of dental provisionals have evolved, as briefly described by Blalock, J., and Cooper, J.. (2011) where they characterized provisionals made of bis-acrylic resin with fluid composites. Also, Avinash, S., and Manzotti, A,. (2012) propose the use of polycarbonate crowns, which are easy and quick to adapt with a good aesthetic result. It suggests the use of fluid resin to unify the tone at the junction of the polycarbonate crown and the acrylic resin once the provisional is exceeded, the disadvantage of this technique is the lack of colors of the prefabricated crowns. Similarly, Barwacz, C., and Hernández, M. (2013) propose to mimic a provisional restoration with natural teeth using color modifiers of photocurable resins (yellow, gray and white).

Although throughout history there have been attempts and proposals for characterization to give a better aesthetic to the provisional ones and avoid the monochromatic appearance of acrylic; The techniques described above present in common that if the tone achieved is not the desired one, this should be removed with strawberries, causing distortions in the restoration or repeating the provisional one. For this reason, the proposed technique allows if the tooth to be extracted can be restored with resin or this integral, can be used as a provisional and generate a more natural appearance in the same dental appointment.

\section{OBJETIVE}

Show an alternative technique for the preparation of a natural tooth provisional in the same dental consultation

\section{MATERIALS AND METHODS}

Clinical case. Male patient of YEARS OF AGE who is presented to the dental office, and to the clinical examination the mobility degree \#\#\#\# of the upper left central incisor is observed for 4 months without pain, radiographically only bone support is diagnosed at the apical level. The incisor does not present any carious lesion, the dental crown is complete.

The irremediable treatment plan is to perform the extraction of the left upper incisor, and at that time the way to perform and a dental provisional that is closest in all diameters to the natural tooth that will be extracted in that same dental consultation should be planned. That is, a similar provisional in cervical-incisal, mesio-distal diameter, color and shape.

The alternative technique that is presented, quickly resolves and responds to the patient's requests, where he requests that the tooth be very natural and that it is not noticed that it is a dental provisional.

The alternative technique is described:

1. Extraction of the left central incisor

2. Bleeding control. (Figures 1-2)

3. The root was cut in an ovoid shape at a distance of nine millimeters to the apical part of the enamel junction with the root cement, to create an ovoid pontic and maintain the shape of the interdental papillae in the area.

4. Height is given according to the upper right Central Incisive

5. The mesiodistal space is respected, that is, the already cut crown is repositioned as the tooth was naturally. (Figures 3-4)

6. The enamel is prepared with $7 \%$ Phosphoric acid and the application of the dental adhesive. That is, the enamel of the Incisor is prepared by the palatal area, and the same clinical procedure is also performed on the upper left lateral incisor and the upper right central incisor, which will function as pillars for the provisional future.(Figure 5)

7. A resin splint is designed on the palatal side, which functions as a means of fixation.

8. It is positioned in the same socket so as not to lose the shape of the mesial and distal incisive papillae.

Figure 1-2 Bleeding control

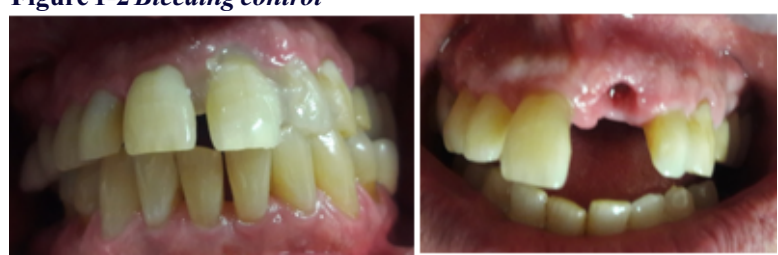

Own source: Estrada, B (2019)

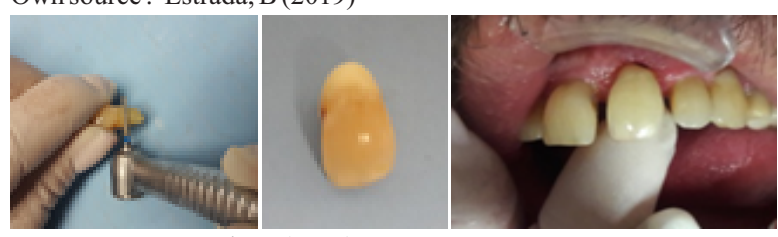

Own source: Estrada, B (2019) 


\section{Figure 5 Adhesion system application}
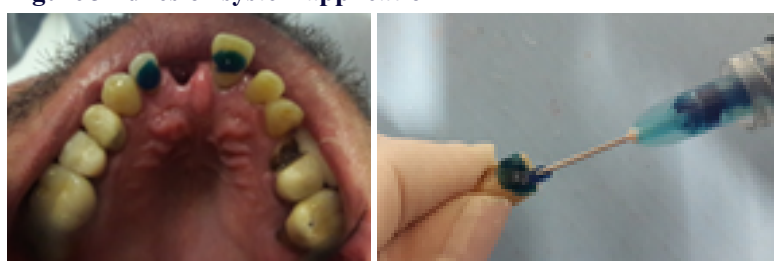

Own source: Estrada, B (2019)

\section{RESULTS}

The patient is pleased with the result of the natural provisional, as he observes that it is his own tooth, that gives him peace of mind and emotionally does not feel that he has lost one more tooth.

At the same time, by giving the cervical heel an ovoidal shape, it causes the healing of the socket to be suitable for the future placement of the crown or pontics of definitive rehabilitation.

This provisional design proposal is made at the same appointment, and the patient never clinically notes that he has lost a tooth. (Figure 6-7)

\section{Figure 6 Resin band fixation}

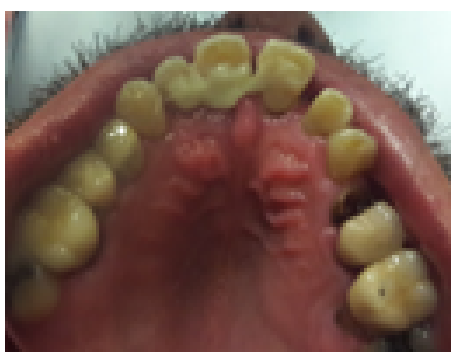

Own source: Estrada, B (2019)

\section{Figure 7 Resin band fixation}

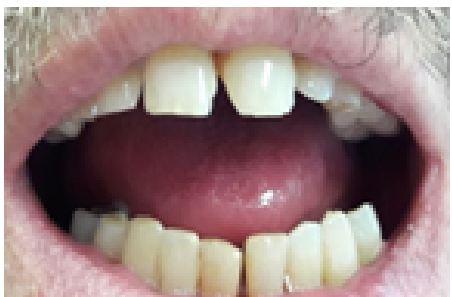

Own source: Estrada, B (2019)

\section{CONCLUSIONS}

This proposal of provisionals with natural teeth, generate an emotional support to the patient when they see their own tooth, since it is one of the patients' concerns, to think that they will be left without a tooth or with a provisional that will be noticed much that is not similar in terms of color and shape to their teeth and it is noted that it is a provisional tooth, especially in the anterior dentition sector.

\section{REFERENCES}

[1] Cho, G. Chee, W. "Custom Characterization of the provisional restoration". The Journal Prosthetic Dentistry. Vol. 69 No. 6, May 1983.

[2] Wassell, R., Ingledew, J., Steele, G. "Crowns and other extra- coronal restorations: provisional restorations". British Dental Journal, Vol. 192, No. 11, June 15, 2002

[3] Blalok, J., Cooper, J, " A technique for effective shade modification of a provisional restoration" The Journal of Prosthetic Dentistry, 2011;105:347-348.

[4] Avinash S. Bidra.J., Manzotti, A." A Direct Technique for Fabricating Esthetic Anterior Fixed Provisional Restorations using Polycarbonate Veneers". Compemdium of continuing education in dentistry. Vol 33, No. 6, June 2012.

[5] Barwacz, C., Hernandez, M. "Direct Extrinsic Characterization, Maximizing Esthetics of Fixed Interim Restorations". Journal of Cosmetics Dentistry. Vol.29, No1, Spring 2013.

[6] Aloul, R., Hansen, C., Nidal S. "Procedure for provisional prosthesis characterization". The Journal of prosthetic Dentistry. December 2001.

[7] Stassler, H.,"Fixed Prosthodontics Provisional Materials: Making the Right Selection " Compemdium of continuing Education in dentistry.. Vol 34, No.1 Jenuary 2013

[8] Dumbrigue, H. "Composite indirect-direct method for fabricating multiple - unit provisional restoration". The Journal of Prosthetic Dentistry The Journal of Prosthetic Dentistryol. Vol. 89 , No. 1, January de 2003

[9] Marcucci, B. "A shade selection technique" The Journal of Prosthetic Dentistry Vol, 89 No. 5 may 2003 